\title{
First Dose Behavioral Tolerance to Phencyclidine on Food-Rewarded Bar Pressing Behavior in the Rat
}

\author{
Diane M. Ruffing and Edward F. Domino \\ Department of Pharmacology, Lafayette Clinic, 951 East Lafayette, Detroit, MI 48207, U.S.A., \\ and The University of Michigan, Ann Arbor, MI 48109, U.S.A.
}

\begin{abstract}
The behavioral effects of single doses of phencyclidine (PCP) were examined in drug-naive adult male Holtzman rats trained to press a bar on a fixed ratio (4) schedule $\left(\mathrm{FR}_{4}\right)$, i.e., a reward of sugarsweetened milk was earned on every fourth bar press. Groups of rats (four to eight rats per group) received specific doses of PCP which were held constant for each group throughout the study. Dose-response curves for PCP given in doses of $1.0,1.8,2.4$, and $3.2 \mathrm{mg} / \mathrm{kg}$ IP were first determined and then redetermined at weekly intervals. A drug-free interval of $7-8$ days was maintained between injections given weekly over a period of 4 weeks. The final dose of PCP was administered after a 4-week drug-free period. Evidence was obtained for first dose behavioral tolerance as shown by the significantly shortened duration of suppression of bar pressing on subsequent injections. Although subsequent weekly effects of equal doses of PCP showed no significant differences, they all differed significantly from the first injection. The reduced response to PCP was shown to be due to learned behavioral tolerance as demonstrated when PCP $(3.2 \mathrm{mg} / \mathrm{kg}$ IP) was given to drug-naive animals in their home cages and 1 week later given the second dose in the operant behavioral situation. Under these circumstances, the second dose of PCP showed a similarly protracted depression of $\mathrm{FR}_{4}$ responding as other animals given the drug for the first time in the operant situation. Subsequent weekly injections in the operant situation produced similar behavioral tolerance.
\end{abstract}

Key words: Phencyclidine - PCP - First dose behavioral tolerance $-\mathrm{FR}_{4}-$ Operant behavior

The unique central nervous system activity of phencyclidine (PCP) is generally acknowledged. It encompasses

Offprint requests to: Reprint Secretary, Lafayette Clinic, 951 E. Lafayette, Detroit, MI 48207, U.S.A. characteristics of a local and general anesthetic with psychomotor stimulation, sedation, and schizophrenomimetic properties (Domino, 1964, 1978; Luby et al., 1962). Currently, PCP is a major drug of abuse. Serious toxicity has been reported from the use of PCP and especially the preparations that are available on the street (Burns and Lerner, 1976; Burns et al., 1975; Eastman and Cohen, 1975).

In view of the influence of behavioral factors on the effects of psychoactive drugs in specific circumstances (LeBlanc et al., 1973; McKearney and Barrett, 1978; Dews, 1962,1978), the study was initiated to compare the possibility of behavioral-environmental factors influencing the effects of PCP. The objectives were to investigate the behavioral effects of PCP coupled with an examination of observed first dose behavioral tolerance.

\section{Materials and Methods}

Subjects. Adult male Holtzman rats at least 90 days old were housed individually in a constant temperature and humidity facility and, maintained at approximately $70 \%$ of their expected free-feeding weight.

Procedures. Food-rewarded bar pressing was established by training rats to press a bar for $1 \mathrm{~h}$ daily to receive $0.01 \mathrm{ml}$ of a sugar waterevaporated milk solution as positive reinforcement. The milk was prepared by combining $400 \mathrm{ml}$ evaporated milk with $400 \mathrm{ml}$ tap water and $60 \mathrm{~g}$ granulated sugar. The daily bar pressing schedule was a fixed ratio (4) $\left(\mathrm{FR}_{4}\right)$, i.e., every fourth bar press earned a reward. Experiments were conducted in a darkened isolated room using Lehigh Valley Electronics rodent operant test cages (model 143-21). Cumulative recorders automatically recorded bar presses, reinforcements, and any disruption of normal bar pressing during daily sessions. After achieving stable $\mathbf{F R}_{4}$ behavior, each rat was then assigned a daily 60 -min bar pressing schedule for at least 5 days prior to any injections. Procedures for training and experiments were similar to those described by Kovacic et al, (1978) and Ruffing et al. (1979). Animals used in this study had no past drug history. To examine the effects of PCP, each assigned group received one specific dose for the entire study with each rat serving as its own control. A drug-free interval of $7-8$ days was observed between injections, with the exception of the last injections, which required a drug-free interval of 4 weeks. Log spaced doses of PCP $(1.0,1.8,2.4$, and $3.2 \mathrm{mg} / \mathrm{kg})$ 
were administered IP to disrupt food-rewarded $\mathrm{FR}_{4}$ bar pressing in a dose-related fashion. Pretreatments with $0.9 \% \mathrm{NaCl}$ were not used for control reactions, since it had been demonstrated in previous studies (using identical as well as similar saline pretreatment schedules) that such vehicle controls revealed no disruptive effects on bar pressing responses or any alteration in drug effect reactions (Kovacic and Domino, 1976; Kovacic et al., 1978).

In the control procedures rats were placed in an operant chamber for 15-20 min of bar pressing, injected IP with PCP, and returned immediately to the operant chamber until the rat recovered and pressed the bar steadily at a rate of $90 \%$ of control for a $60-\mathrm{min}$ period. Groups of rats, receiving specific PCP doses, were given the same dose throughout the study. After determining the duration of the initial response for PCP doses $1.0,1.8,2.4$, and $3.2 \mathrm{mg} / \mathrm{kg} \mathrm{IP}$ ), each of these groups (groups, $A-D$, respectively) were retested to resolve the question of possible long-term PCP effects and to substantiate reproducible behavioral drug results. The control retesting procedure was repeated for 3 uninterrupted weeks. Drug-free intervals of $7-8$ days were observed between injections one to three and a 4-week drug-free interval for the final injection. At least 2 consecutive days of 60 -min bar pressing sessions were required for all groups prior to additional PCP injections. At this time, typical drug-free behavioral bar pressing activity at control rates was recorded. Behavioral responses were noted for the duration of the drug effects.
A second $3.2 \mathrm{mg} / \mathrm{kg}$ PCP control groups was instituted to clarify the influence of environmental circumstances modifying the behavioral effects of PCP. The second group (group E) was exposed to an identical control schedule with the exception that the initial injection was administered in the home cage following the bar pressing session (rather than the usual procedure of injecting in the operant chamber during the bar pressing session). Behavioral responses were noted for duration of the drug effects.

Three additional groups of eight animals each were used to compare the effects of PCP $(1.0$ and $1.8 \mathrm{mg} / \mathrm{kg})$ to those of N,Ndimethyltryptamine (DMT) $(3.2$ and $10.0 \mathrm{mg} / \mathrm{kg})$ and LSD $(0.1 \mathrm{mg} / \mathrm{kg})$. Identical procedures were followed with all groups, with the exception that the total number of injections per group was two.

Data Analysis. The duration of PCP effects was measured by the horizontal line generated from the cumulative recorder during any disruption of bar pressing behavior. Paired-comparison $t$-tests were used to statistically analyze the data and were calculated according to Snedecor (1956) using the value of $P<0.05$ as significant.

Drugs. Phencyclidine $\mathrm{HCl}$ (Sernylan, Bio-Ceutic Laboratories, St. Joseph, MO) was diluted with $0.9 \% \mathrm{NaCl}$ to the appropriate concentrations. DMT (Sigma Chemical, St. Louis, MO) was prepared by dissolving the free base in $1 \mathrm{~N} \mathrm{HCl}$, adding $0.9 \% \mathrm{NaCl}$, and adjusting the $\mathrm{pH}$ to $4.5-5.5$ with $0.1 \mathrm{~N} \mathrm{NaOH}$. LSD (Delysid) doses

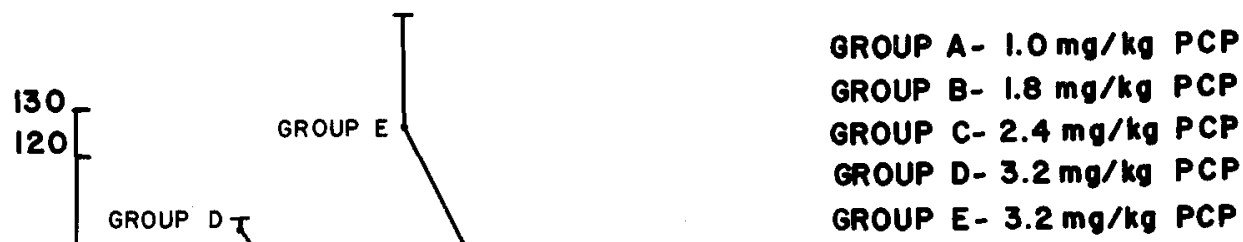

Fig. 1. Dose effect of PCP doses $(1.0,1.8,2.4$, and $3.2 \mathrm{mg} / \mathrm{kg})$ in the suppression of $\mathrm{FR}_{4}$ behavior in the rat. In groups $A-D$, PCP control injections one to three were administered after 7-8 day drug-free intervals between injections, while a 4 week drug-free interval was observed for the final PCP control. Each group of five to nine rats and assigned PCP dose was held constant for the entire study with each rat serving as its own control. All injections were administered IP. Group E (five rats) received the first PCP injection while in the home cage with succeeding injections administered in the operant chamber situation. When groups $D$ and $E$ were initially injected in the operant chamber, significant reductions of the initial drug response occurred in the proceeding injections (injection 2 in group $\mathrm{D}$ and injection 3 in group $\mathrm{E}_{1}$ ). In group $\mathrm{E}$, seven day drug-free intervals were observed between injections one to four with each rat serving as its own control. In this and the subsequent figure paired comparison Student's $t$-tests were done in which the following symbols apply: ${ }^{*} P<0.05$; ${ }^{* *} P<0.01$; *** $P>0.001$ 
refer to LSD-25 substance obtained from the National Institute on Drug Abuse. All doses for PCP, DMT, and LSD refer to free base.

\section{Results}

Doses of 1.0, 1.8, 2.4, and $3.2 \mathrm{mg} / \mathrm{kg}$ PCP disrupted bar pressing behavior in a dose-related fashion and produced gross behavioral reactions within approximately $5 \mathrm{~min}$ following IP injections. Gross behavioral reactions included marked ataxia, motor hyperactivity, repetitious head and body movements, cage circling, crawling in a flattened position, walking backwards, occasional Straub tail, excessive floor sniffing, muscular twitching, salivation, and lacrimation. These observations are consistent with reactions reported by Domino (1964), Chait and Balster (1978), and Chen et al. $(1959,1965)$. After cessation of bar pressing, the rats would begin and continue bar pressing for $60 \mathrm{~min}$ at preinjection rates.

Figure 1 illustrates (groups $A-D$ ) the longer duration of the first dose behavioral effects with reproducible stable responses in succeeding weekly doses. The reduction of drug responses noted between the first and second injections (Fig. 1) was shown to be due to learned behavioral tolerance. Figure 1 shows that when the first dose environmental situation was altered in group E (by administering the first dose of PCP to rats in their home cages and succeeding weekly doses in the operant chamber), the longer duration of drug-induced response disruptions occurred with the second dose and the markedly reduced drug response disruptions were maintained following the third dose, etc.

The prolonged suppression of $\mathrm{FR}_{4}$ behavior was exclusive for the first dose and no changes in drug response were noted following a 4 week drug-free interval (Fig. 1).

The observed first dose tolerance is unique to PCP when compared with other hallucinogenic drugs (on identical schedules) in drug-naive rats given DMT (3.2 and $10.0 \mathrm{mg} / \mathrm{kg} \mathrm{IP})$ and LSD $(0.1 \mathrm{mg} / \mathrm{kg} \mathrm{IP})$. Figure 2 shows two consecutive injections of each drug while observing a seven day drug-free interval between the first and second injections.

Because of deteriorating health and/or unsatisfactory drug-free bar pressing records, several rats had to be excluded from the study resulting in a change in the number $(N)$ of rats per group. The cause of this deterioration was undetermined, but seemed directly related to toxic PCP effects.
PCP- $1.8 \mathrm{mg} / \mathrm{kg}$

$(N=6)$
DMT- 10. $\mathrm{mg} / \mathrm{kg}$

$(N=8)$

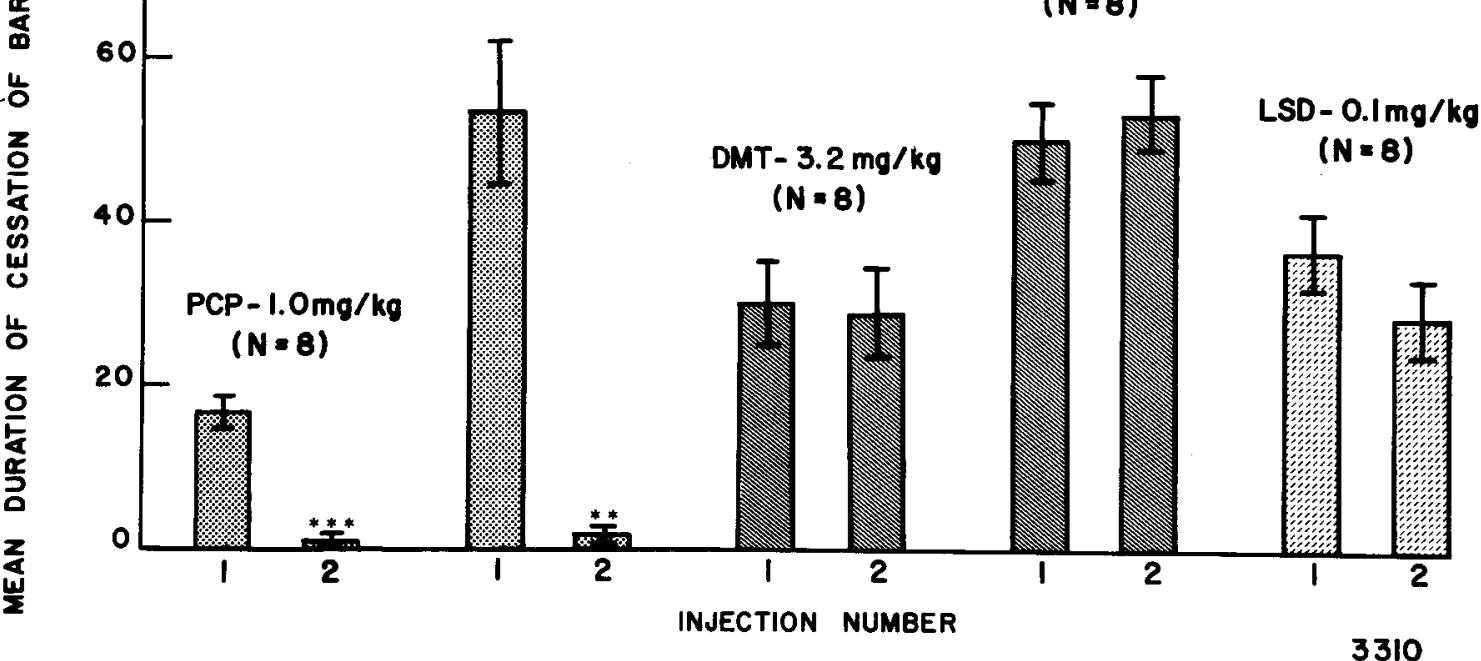

Fig. 2. Comparison of $\mathrm{FR}_{4}$ behavioral drug effects of $\mathrm{PCP}(1.0$ and $1.8 \mathrm{mg} / \mathrm{kg}), \mathrm{DMT}(3.2$ and $10.0 \mathrm{mg} / \mathrm{kg})$, and LSD $(0.1 \mathrm{mg} / \mathrm{kg})$. Injections were administered observing seven day drug-free intervals between injections. All animals were drug-naive before the initial dose of each drug shown. All injections were administered IP, with eight rats in the PCP $1.0 \mathrm{mg} / \mathrm{kg}$ group; six rats in the PCP $1.8 \mathrm{mg} / \mathrm{kg}$ group; and eight rats representing the DMT and LSD groups. First dose behavioral tolerance is shown to be exclusive for the PCP groups in the FR $\mathrm{R}_{4}$ behavioral situation 


\section{Discussion}

In spite of the evidence that behavioral tolerance has been observed to a large number of psychoactive drugs (Krasnegor, 1978), to our knowledge, it has not been reported with PCP, and especially so dramatically with the first dose as reported here.

Consistent gross behavioral reactions to PCP were seen throughout the study, although all groups displayed a large variability in the duration of drug effect times and a few select rats showed greater sensitivity and/or longer durations of $\mathrm{FR}_{4}$ suppression. As the study progressed, rats became increasingly difficult to handle and unusually aggressive. After a period of $3-4$ months following the concluding PCP injections, an astounding $45 \%$ mortality rate was noted. In our experience with other drugs, such a deterioration in performance is highly unusual, suggesting chronic toxicity to PCP. Nonspecific toxicity, as well as longterm behavioral effects from PCP have been reported (Burns et al., 1975; Linden et al., 1975; Tong et al., 1975; Fauman et al., 1975; James and Schnoll, 1976). Further research on chronic PCP toxicity is clearly indicated.

The first dose PCP induced behavioral tolerance further emphasizes the profound influence of behavioral factors on the effects of psychoactive drugs. The use of animals trained on various operant schedules to examine the effects of various drugs should be carefully evaluated in view of the striking evidence of behavioral tolerance to a single dose of PCP.

Whether single dose behavioral PCP tolerance applies to other behavioral paradigms in the rat and other species, including man, remains for future research to answer.

Acknowledgements. This research was supported in part by NIDA grant 1 RO1 DA-01531-01A3 and United States - Israel Binational Science Foundation grant 1638.

\section{References}

Burns, R. S., Lerner, S. E.: Phencyclidine: An emerging drug problem. Clin. Toxicol. 9, 477-501 (1976)

Burns, R. S., Lerner, S. E., Corrado, R., James, S. H., Schnoll, S. H.: Phencyclidine. States of acute intoxication and fatalities. West. J. Med. 123, 345-349 (1975)

Chait, L. D., Balster, R. L.: The effects of acute and chronic phencyclidine in schedule-controlled behavior in the squirrel monkey. J. Pharmacol. Exp. Ther. 204, 77-87 (1978)
Chen, G., Ensor, C. R., Russel, D., Bohner, B.: The pharmacology of 1-(1-phenylcyclohexyl)piperidine hydrochloride. J. Pharmacol. Exp. Ther. 127, $241-250$ (1959)

Chen, G., Ensor, C. R., Bohner, B.: An investigation on sympothomimetic properties of phencyclidine by comparison with cocaine and desoxyephedrine. J. Pharmacol. Exp. Ther. 149, 71-78 (1965)

Dews, P. B.: Psychopharmacology. In: Experimental foundations of clinical psychology, A. J. Backrack, ed., pp. 423-441. New York: Basic Books 1962

Dews, P. B.: Behavioral tolerance. NIDA Res. Monogr. 18, 18-26 (1978)

Domino, E. F.: Neurobiology of phencyclidine (Sernyl), a drug with an unusual spectrum of pharmacological activity. Int. Rev. Neurobiol. 6, 303-347 (1964)

Domino, E. F.: Some aspects of the pharmacology of phencyclidine. In: The psychopharmacology of hallucinogens, R. C. Stillman, R. E. Willette, eds., pp. 105-117. New York: Pergamon 1978

Eastman, J. W., Cohen, S. N.: Hypertensive crisis and death associated with phencyclidine poisoning. J. Am. Med. Ass. 231, $1270-1271(1975)$

Fauman, B., Baker, L. W., Coppkson, P. Rosen, Segal, M. B.: Psychosis induced by phencyclidine. J. Am. Coll. Emer. Physicians 4, 223 (1975)

James, S. H., Schnoll, S. H. : Phencyclidine: Tissue distribution in the rat. Clin. Toxicol. 9, 573-582 (1976)

Kovacic, B., Domino, E. F.: Tolerance and limited cross-tolerance to the effects of N,N-dimethyltryptamine (DMT) and lysergic acid diethylamide-25 (LSD) on food-rewarded bar pressing in the rat. J. Pharmacol. Exp. Ther. 197, 495-502 (1976)

Kovacic, B., Lu, L. J. Wang, Ruffing, D., Domino, E. F.: Interactions of partial LSD analogs with behavioral disrupting effects of LSD and DMT in the rat. Eur. J. Pharmacol. 47, $37-$ $44(1978)$

Krasnegor, N. A., ed. : Behavioral tolerance: Research and treatment implications. NIDA Res. Monogr. 18, 1-151 (1978)

LeBlanc, A. E., Gibbins, R. J., Kalant, H.: Behavioral augmentation of tolerance to ethanol in the rat. Psychopharmacologia 30, $117-122$ (1973)

Linden, C. B., Lovejoy, F. H., Jr., Costello, C. E.: Phencyclidine. J. Am. Med. Ass. 234, 513-516 (1975)

Luby, E. D., Gottlieb, J., Cohen, B., Rosenbaum, G., Domino, E. F.: Model psychoses and schizophrenia. Am. J. Psychiatry 119, 61 67 (1962)

McKearney, J. W., Barrett, J. E.: Schedule-controlled behavior and the effects of drugs. In: Contemporary research in behavioral pharmacology, D. E. Blackman, D. J. Sanger, eds., pp. 1-68. New York: Plenum 1978

Ruffing, D., Kovacic, B., Demetriou, S., Domino, E. F. : Naloxone enhancement of DMT- and LSD-25-induced suppression of food-rewarded bar pressing behavior in the rat. Psychopharmacology 62, 207-210 (1979)

Snedecor, G. W.: Statistical methods. Ames: Iowa State College Press 1956

Tong, T. G., Benowitz, N. L., Becker, C. E., Forni, P. J., Boerner, U.: Phencyclidine poisoning. J. Am. Med. Ass. 234, 512 - 513 (1975)

Received July 24, 1979; Final Version February 7, 1980 